\title{
Comparison of different maximum safe levels in fortified foods and supplements using a probabilistic risk assessment approach
}

\author{
Ariane Dufour ${ }^{1}$, Sandrine Wetzler ${ }^{2}$, Mathilde Touvier $^{3}$, Sandrine Lioret ${ }^{1}$, Jennifer Gioda ${ }^{2}$, Lionel Lafay ${ }^{1}$, \\ Carine Dubuisson ${ }^{1}$, Gloria Calamassi-Tran ${ }^{1}$, Esther Kalonji ${ }^{2}$, Irène Margaritis ${ }^{2}$ and Jean-Luc Volatier ${ }^{4}$ \\ ${ }^{1}$ Dietary Survey Unit - Nutritional Epidemiology, French Agency for Food, Environmental and Occupational Health Safety \\ (ANSES), 27-31 avenue du Général Leclerc, F-94701 Maisons-Alfort Cedex, France \\ ${ }^{2}$ Nutrition Risk Assessment Unit, French Agency for Food, Environmental and Occupational Health Safety (ANSES), 27-31 avenue \\ du Général Leclerc, F-94701 Maisons-Alfort Cedex, France \\ ${ }^{3}$ UREN, UMR U557 Inserm/U1125 Inra/Cnam/Paris 13, CRNH IdF, SMBH Paris 13, 74 rue Marcel Cachin, F-93017 Bobigny \\ Cedex, France \\ ${ }^{4}$ Office of Scientific Support for Risk Assessment, French Agency for Food, Environmental and Occupational Health Safety \\ (ANSES), 27-31 avenue du Général Leclerc, F-94701 Maisons-Alfort Cedex, France
}

(Received 12 October 2009 - Revised 8 June 2010 - Accepted 10 June 2010 - First published online 2 August 2010)

\begin{abstract}
Different European institutions have developed mathematical models to propose maximum safe levels either for fortified foods or for dietary supplements. The objective of the present study was to compare and check the safety of these different maximum safe levels (MSL) by using a probabilistic risk assessment approach. The potential maximum nutritional intakes were estimated by taking into account all sources of intakes (base diet, fortified foods and dietary supplements) and compared with the tolerable upper intake levels for vitamins and minerals. This approach simulated the consequences of both food fortification and supplementation in terms of food safety. Different scenarios were tested. They are the result of the combination of several MSL obtained using the previous models. The study was based on the second French Individual and National Study on Food Consumption performed in 2006-7, matched with the French food nutritional composition database. The analyses were based on a sample of 1918 adults aged 18-79 years. Some MSL in fortified foods and dietary supplements obtained independently were protective enough, although some others could lead to nutritional intakes above the tolerable upper intake levels. The simulation showed that it is crucial to consider the inter-individual variability of fortified food intakes when setting MSL for foods and supplements. The risk assessment approach developed here by integrating the MSL for fortified foods and dietary supplements is useful for ensuring consumer protection. It may be subsequently used to test any other MSL for vitamins and minerals proposed in the future.
\end{abstract}

Vitamins: Minerals: Dietary supplements: Fortified foods: Simulations: Tolerable upper intake levels

European Regulation (EC) no. 1925/2006 ${ }^{(1)}$ on the addition of vitamins and minerals to foods has been in force since 1 July 2007. It consists in establishing a harmonised Community basis on such practices in order to guarantee both consumer safety and free movement of goods. The main issue remaining is to set maximum safe levels of vitamins and minerals in fortified foods which take into account tolerable upper intake levels (UL), micronutrient intakes from all dietary sources and population reference intakes. With the growing use of supplements ${ }^{(2)}$, it becomes necessary to also consider nutrient intakes from this source.

Different models have already been developed to set maximum safe levels either for fortified foods or for dietary supplements ${ }^{(3-8)}$. Apart from the German Federal Institute for Risk Assessment (BFR) model ${ }^{(7,8)}$, these models lead independently to maximum safe levels either for fortified foods $\left(\mathrm{MSL}_{\mathrm{f}}\right)$ or for dietary supplements $\left(\mathrm{MSL}_{\mathrm{s}}\right)$. But the $\mathrm{MSL}_{\mathrm{f}}$ and $\mathrm{MSL}_{\mathrm{s}}$ are dependent on each other and have to be taken into consideration simultaneously. To our knowledge there is no approach based on these maximum safe levels which attempts to estimate the overall vitamin or mineral intakes and to check their safety.

In 2000, the French Food Safety Agency (AFSSA) developed a probabilistic risk assessment approach for assessing the safety of maximum safe levels of vitamins and minerals, but only for food fortification ${ }^{(9)}$. This method simulated the consequences of food fortification in terms of food safety by comparing high nutrient intakes with the UL. The present study had already been used as a validation tool by Flynn et al. ${ }^{(3)}$. Moreover, a public health approach had been

Abbreviations: AFSSA, French Food Safety Agency; BFR, German Federal Institute for Risk Assessment; ERNA, European Responsible Nutrition Alliance; ILSI, International Life Sciences Institute; INCA2, second French Individual and National Study on Food Consumption; MSL $_{\mathrm{f}}$, maximum safe level for fortified foods; $\mathrm{MSL}_{\mathrm{s}}$, maximum safe level for dietary supplements; UL, tolerable upper intake level.

* Corresponding author: Ariane Dufour, fax +3314977 38 92, email ariane.dufour@anses.fr 
suggested to evaluate the relevance of vitamins and minerals for basic food fortification ${ }^{(10)}$. Foods contributing the most to vitamin and mineral intakes were also defined ${ }^{(11)}$. Derived from AFSSA's previous work, the present study proposes a new approach to estimate the impact of consumption of fortified foods and dietary supplements on total micronutrient intakes in adults. This approach permits testing and validation of the maximum safe levels of vitamins or minerals for fortification and supplementation set by different mathematical models for food safety (Fig. 1). These values were simultaneously tested on recent representative French consumption data. It should be pointed out that nutritional benefit has not been considered in this approach. Consequently the present study only takes into account consumer safety.

\section{Subjects, methods and procedures used}

\section{Subjects and design}

The present study used data from the second French Individual and National Study on Food Consumption (INCA2) ${ }^{(12)}$. The survey was carried out by the Dietary Survey Unit-Nutritional Epidemiology (OCA-EN) of AFSSA between December 2005 and May 2007 in order to take into account seasonal variations in food intake. It involved 4079 participants aged 3-79 years (2624 adults and 1455 children aged 3-17 years) living in mainland France. The participants were selected using a three-stage cluster sampling technique stratified by region and size of urban area. The random selection of households was made from the French National Institute for Statistics and Economic Studies (INSEE) 1999 General Population Census $^{(13)}$ supplemented by the Survey Database for New Housing (BSLN) and Automated Processing and Information System for Basic Data on Housing and Premises (SITADEL) databases for homes built after 1999. The survey design and sampling frame were previously described in more detail in the INCA2 report $^{(12)}$ in particular.

To ensure the national representativeness of the final samples, data were weighted using a post-stratification algorithm $^{(14)}$ according to sociodemographic criteria: region, size of urban area, size of household, sex, age, profession and social category of head of household, and season. Moreover, under-reporter adults (defined as participants who intentionally or unintentionally underestimate their energy intakes compared with their needs) were identified using the Goldberg et al. criterion and excluded from the analyses ${ }^{(15)}$.

(a)

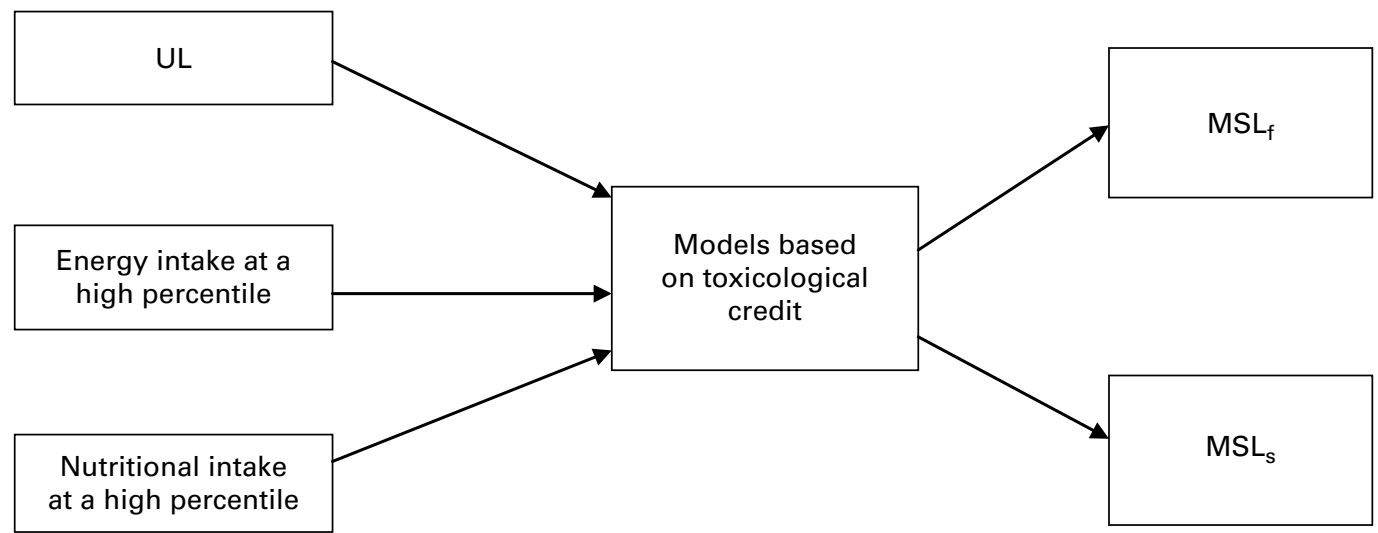

(b)

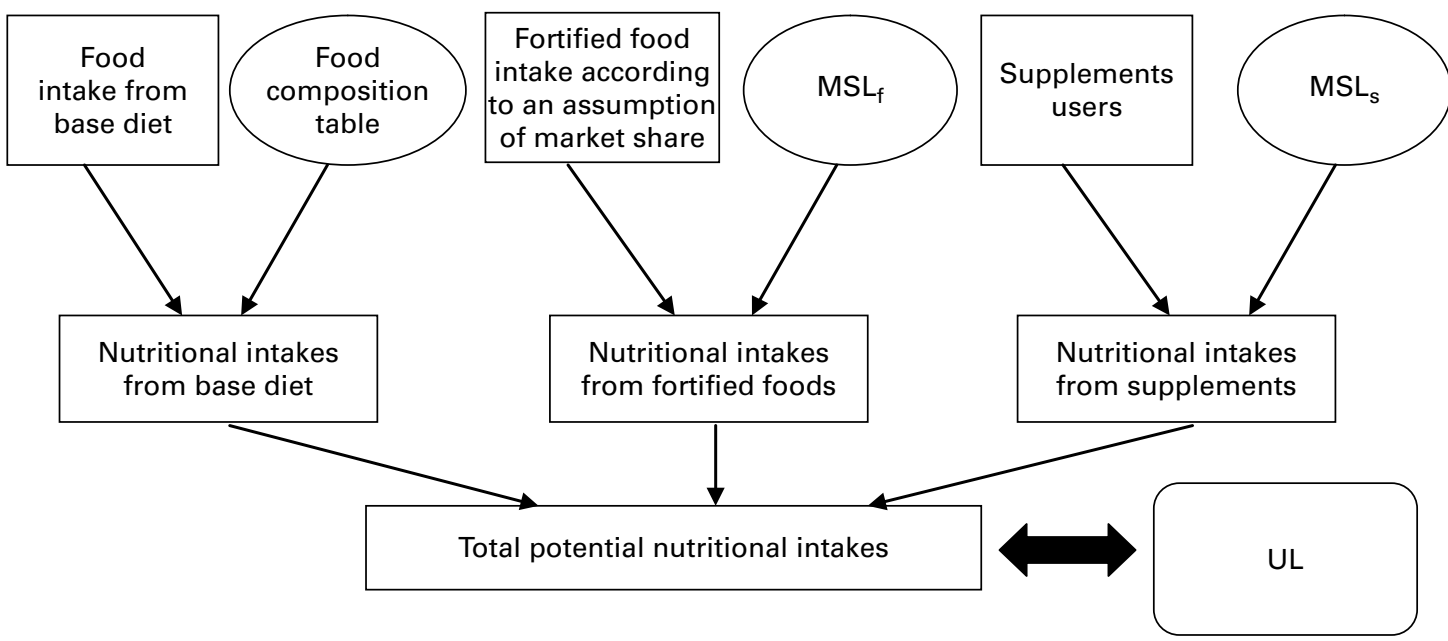

Fig. 1. Differences between principles of models which set maximum safe levels (a) and the French Food Safety Agency (AFSSA) risk assessment approach (b). $\mathrm{UL}$, tolerable upper intake level; $\mathrm{MSL}_{\mathrm{f}}$, maximum safe level for fortified foods; $\mathrm{MSL}_{\mathrm{s}}$, maximum safe level for dietary supplements. 
The following analyses were based on a sample of 1918 adults considered as plausible reporters of energy intake.

The INCA2 survey was approved by the French data protection authority (Commission Nationale Informatique et Libertés) and the French national council for statistical information (Conseil National de l'Information Statistique).

\section{Measurements}

Consumption data. Dietary intakes were reported using a $7 \mathrm{~d}$ open-ended food record: food and beverages consumed at each main meal (breakfast, lunch and dinner) and betweenmeal snacks were described in detail. Portion sizes were estimated with the help of a validated picture booklet ${ }^{(16)}$. Foods collected in the dietary records were codified according to a food list drawn up specifically for the study (containing forty-three food groups and 1342 food items). As the nomenclatures were compatible, consumption data were matched with the French food composition databank from the French Information Centre on Food Quality (CIQUAL) $^{(17)}$. Each food item is linked to a nutritional composition vector containing macronutrients, twelve vitamins and eleven minerals.

Food supplement data. For the first time in a nationally representative French dietary survey, consumption of dietary supplements was also assessed: firstly during the $7 \mathrm{~d}$ of the study using a $7 \mathrm{~d}$ dietary supplement record and secondly, during the previous 12 months, using a face-to-face interview. The definition of a food supplement used in the INCA2 study was not restricted to the regulatory definition but also included drugs containing micronutrients. Dietary supplements were therefore defined as vitamins, minerals, plant extracts or concentrates, amino acids, proteins, essential fatty acids, phyto-oestrogens, or any other supplement to the diet taken as pills, tablets, powder or syrup.

\section{Maximum safe levels of vitamins and minerals in fortified foods and dietary supplements set by different models}

Different institutions have developed models to estimate maximum safe levels of vitamins and minerals in fortified foods, as well as in dietary supplements. The Appendix summarises the different models and gives further details on the mathematical formulations. Flynn first proposed an original model (also called the International Life Sciences Institute (ILSI) model) for the safe addition of vitamins and minerals to foods ${ }^{(3,18)}$. This model estimated the level of each nutrient that can be safely added to foods, to minimise the risk of excessive intakes. It was based on the following parameters: UL, current micronutrient intake from the base diet at the 95th percentile, energy intake at the 95th percentile and fraction of food on the market that is available for fortification. Another study from the Danish Institute for Food and Veterinary Research (DFVR) ${ }^{(5)}$ proposed extending the model developed by Flynn et $a{ }^{(3)}$ by considering the common use of micronutrient supplements. The BFR proposed a method for deriving maximum safe levels of vitamins and minerals for both fortified foods and supplements ${ }^{(7,8)}$. The toxicological credit or maximum amount for safe addition of vitamins and minerals to food (including dietary supplements) resulted from the difference between the UL and the highest percentile (95th or 99th percentile) of nutrient intake from the base diet. This residual amount constituted the total amount available for dietary supplements and fortified foods. The percentage of this amount allocated to dietary supplements or fortified foods may be between 0 and $100 \%$. However, the sum of the two percentages may not exceed $100 \%$. Richardson ${ }^{(6)}$ provided a system (also known as the European Responsible Nutrition Alliance (ERNA) model) for categorising nutrients according to the risk of exceeding their UL. The qualitative risk characterisation of nutrients was based on the concept of Population Safety Index. The micronutrients were classified into three groups: group A (no evidence of risk), group B (low risk) and group C (potential risk). This risk management model was applied to determine the maximum safe level for vitamins and minerals in dietary supplements.

\section{Statistical analysis}

French Food Safety Agency (AFSSA) simulation approach developed to estimate nutritional intakes taking into account the maximum safe levels for fortified foods and dietary supplements. The present study does not claim to add yet another mathematical model for setting the maximum safe levels for vitamins and minerals. The aim of this paper was to succeed in estimating the overall potential maximum nutritional intakes (Fig. 1). The $\mathrm{MSL}_{\mathrm{f}}$ and $\mathrm{MSL}_{\mathrm{s}}$ obtained using the different existing models were simultaneously tested according to different scenarios on the recent, detailed and representative French consumption data from the INCA2 survey $^{(12)}$. This estimation was based on a Monte Carlo probabilistic simulation. Total nutritional intakes in the population resulted from the sum of the three intake sources: base diet, i.e. 'common' foods, fortified foods and dietary supplements. Nevertheless, it should be pointed out that fortification and supplementation differ in terms of consumer decision process.

The estimation of nutritional intakes by the base diet is deterministic. It was obtained by linking French consumption data with the food composition table ${ }^{(17)}$. However, the particular case of breakfast cereals should be pointed out. Indeed, since almost all breakfast cereals are already fortified in France, the food composition database of the base diet included these particular fortified foods.

Apart from breakfast cereals, since we did not have precise data on fortified food intake available to date, the method developed to estimate nutritional intakes from this source was probabilistic. First of all, a list of foods consumed in the INCA2 study that could be fortified was drawn up. Nonprocessed foods such as eggs, meat and poultry, offal, fruit, vegetables, traditional foods like some cheeses, beverages such as water and alcoholic drinks were excluded. The final list contained 743 items representing $55 \%$ of the food items from the exhaustive INCA2 nomenclature. Then, for each individual, foods were randomly selected from this list based on a theoretically defined individual market share of the fortifiable foods. These were not mean market shares at the population level but maximum market shares that could be reached by consumers interested in vitamins and minerals. Market shares of 10 and $25 \%$ appeared to be rational and realistic choices given existing information on fortification 
and $50 \%$ represented a high assumption for the share of fortified foods that did not seem possible to exceed. The case of a market share of $0 \%$ was also considered and corresponded to a situation with only supplements and no fortification in the diet. According to this method, each participant in the INCA2 study would therefore consume, in theory, some foods that were fortified and others that were non-fortified throughout the week. For randomly selected fortified foods, the nutritional intake was calculated using the $\mathrm{MSL}_{\mathrm{f}}$ estimated by the models previously presented instead of the nutritional content from the food composition table.

For the fraction of the population consuming dietary supplements, intakes through such products had to be estimated. The proportion of adult supplement users in INCA2 was about $11 \%$ for the week and nearly $20 \%$ considering the last 12 months $^{(12)}$. Our assumption was that, on every day of consumption, supplement users took the maximum safe level (defined by the maximum daily amount $\mathrm{MSL}_{\mathrm{s}}$ ) for every nutrient considered. Consequently, the supplement composition table was not used in the present study to estimate the nutritional intake from supplements. Intakes via this source were estimated using the maximum safe levels set for supplements. Daily intakes from dietary supplements were then added to the intakes estimated from the base diet and fortified foods for the subpopulation of supplement users declaring consumption during the $7 \mathrm{~d}$ of the survey period.

The simulations to estimate the overall maximum daily intake from all sources were performed nutrient by nutrient. Among the twenty-three micronutrients available in our database, ten had a UL defined by the Scientific Committee on Food $^{(19)}$ : five vitamins (retinol, vitamins D, E, B 6 , folic acid) and five minerals ( $\mathrm{Ca}, \mathrm{Cu}, \mathrm{I}, \mathrm{Se}$ and $\mathrm{Zn}$ ). For these ten nutrients, it was possible to ascertain the proportion of individuals presenting a risk of exceeding the UL, according to the different scenarios and for a given market share of fortified foods.

Statistical analyses were conducted using the Statistical Analysis System software package version 9.1 (SAS Institute Inc., Cary, NC, USA).

Description of the different scenarios tested. To estimate the potential maximum daily nutritional intakes from the different dietary sources (base diet, fortified foods and dietary supplements) with the procedure described above, there were many conceivable scenarios based on the different calculated $\mathrm{MSL}_{\mathrm{f}}$ and $\mathrm{MSL}_{\mathrm{s}}$.

For fortified foods, three series of $\mathrm{MSL}_{\mathrm{f}}$ were obtained from the ILSI model ${ }^{(3)}$, the Danish Institute for Food and Veterinary
Research (DFVR) model ${ }^{(5)}$ and the BFR model ${ }^{(7,8)}$, to which a fourth series has been added (conventional assumption of fortification up to $15 \%$ of the European recommended daily allowance for $100 \mathrm{kcal}(418 \mathrm{~kJ})$ of food, which is not related to the regulation on nutritional labelling). For dietary supplements, there were two series of values (maximum daily intake) obtained from the ERNA ${ }^{(6)}$ and $\operatorname{BFR}^{(7,8)}$ models, as well as an additional series based on the French regulatory values ${ }^{(20)}$.

A selection of five scenarios summarised in Table 1 was explored out of the twelve possible combinations of the four series of $\mathrm{MSL}_{\mathrm{f}}$ and the three series of $\mathrm{MSL}_{\mathrm{s}}$ : the model presented by the BFR, setting the maximum safe level for both fortified foods and dietary supplements, is a scenario in itself (scenario 4); the combination of ILSI's fortification levels and ERNA's dietary supplement levels is a scenario presenting high levels in both cases (scenario 1); lastly, with no other data on dietary supplements, it was agreed to combine the three other models setting fortification levels with the values set by the French regulation in 2006 for dietary supplements (scenarios 2, 3 and 5). Table 2 summarises the different $\mathrm{MSL}_{\mathrm{f}}$ and $\mathrm{MSL}_{\mathrm{s}}$ values obtained by the models and considered in the five different scenarios.

\section{Results}

\section{Nutrient intake from the base diet}

Table 3 presents the daily intake distributions (mean, SD, percentiles) from the base diet (excluding fortified foods and dietary supplements) for the ten nutrients selected among non-under-reporter adults in the INCA2 study. This table also indicates for each micronutrient and for the adult population the estimated average requirement and the French population reference intake values as well as the UL set at European Union level (European Food Safety Agency and the Scientific Committee on Food). For some nutrients such as retinol, folic acid, $\mathrm{Ca}, \mathrm{Cu}$ and $\mathrm{Zn}$, the UL are not very far from the higher percentile of distribution (less than twice).

\section{Results with the different scenarios}

Results regarding nutritional intakes using our approach do not represent actual current intakes in the French adult population, but rather potential nutritional intakes under hypotheses taking into account maximum safe levels for fortified foods and dietary supplements and assumptions about the proportion of fortifiable foods in the diet of consumers.

Table 1. Selected scenarios combining maximum safe levels for fortified foods and for dietary supplements out of the twelve possible combinations

\begin{tabular}{|c|c|c|c|}
\hline Supplements... & ERNA/Richardson ${ }^{(6)}$ & BFR/Domke ${ }^{(7,8)}$ & French regulation - Order of 9 May $2006^{(20)}$ \\
\hline \multicolumn{4}{|l|}{ Fortified foods } \\
\hline ILSI/Flynn ${ }^{(3)}$ & Scenario 1 & - & Scenario 2 \\
\hline DFVR/Rasmussen ${ }^{(5)}$ & - & - & Scenario 3 \\
\hline BFR/Domke ${ }^{(7,8)}$ & - & Scenario 4 & - \\
\hline $15 \%$ of RDA & - & - & Scenario 5 \\
\hline
\end{tabular}

ERNA, European Responsible Nutrition Alliance; BFR, Federal Institute for Risk Assessment; ILSI, International Life Sciences Institute; DFVR, Danish Institute for Food and Veterinary Research; RDA, European Recommended Daily Allowance. 
Table 2. Maximum safe level (MSL) values estimated using the different models for ten selected nutrients and applied to the five scenarios of simulation

\begin{tabular}{|c|c|c|c|c|c|c|}
\hline Nutrient & $\mathrm{MSL}^{*}$ & Scenario 1 & Scenario 2 & Scenario 3 & Scenario 4 & Scenario 5 \\
\hline \multicolumn{7}{|l|}{ Vitamins } \\
\hline \multirow[t]{2}{*}{ Retinol } & $\mathrm{MSL}_{\mathrm{f}}(\mu \mathrm{g} / 100 \mathrm{kcal})$ & 0 & 0 & 0 & 0 & 120 \\
\hline & $\mathrm{MSL}_{s}(\mu \mathrm{g} / \mathrm{d})$ & 1000 & 800 & 800 & 400 & 800 \\
\hline \multirow[t]{2}{*}{ Vitamin D } & $\mathrm{MSL}_{\mathrm{f}}(\mu \mathrm{g} / 100 \mathrm{kcal})$ & 9 & 9 & 3 & 0 & 0.75 \\
\hline & $\mathrm{MSL}_{\mathrm{s}}(\mu \mathrm{g} / \mathrm{d})$ & 35 & 5 & 5 & 5 & 5 \\
\hline \multirow[t]{2}{*}{ Vitamin E } & $\mathrm{MSL}_{f}(\mathrm{mg} / 100 \mathrm{kcal})$ & 218 & 218 & 32 & 0 & 1.5 \\
\hline & $\mathrm{MSL}_{\mathrm{s}}(\mathrm{mg} / \mathrm{d})$ & 970 & 30 & 30 & 15 & 30 \\
\hline \multirow{2}{*}{ Vitamin $\mathrm{B}_{6}$} & $\mathrm{MSL}_{f}(\mathrm{mg} / 100 \mathrm{kcal})$ & 5 & 5 & 1 & 1.2 & 0.3 \\
\hline & $\mathrm{MSL}_{\mathrm{s}}(\mathrm{mg} / \mathrm{d})$ & 93 & 2 & 2 & 5.4 & 2 \\
\hline \multirow[t]{2}{*}{ Folic acid } & $\mathrm{MSL}_{f}(\mu \mathrm{g} / 100 \mathrm{kcal})$ & 122 & 122 & 45 & 200 & 30 \\
\hline & $\operatorname{MSL}_{s}(\mu \mathrm{g} / \mathrm{d})$ & 600 & 200 & 200 & 400 & 200 \\
\hline \multicolumn{7}{|l|}{ Minerals } \\
\hline \multirow[t]{2}{*}{$\mathrm{Ca}$} & $\mathrm{MSL}_{f}(\mathrm{mg} / 100 \mathrm{kcal})$ & 30 & 30 & 43 & 0 & 120 \\
\hline & $\mathrm{MSL}_{\mathrm{s}}(\mathrm{mg} / \mathrm{d})$ & 1500 & 800 & 800 & 500 & 800 \\
\hline \multirow[t]{2}{*}{$\mathrm{Cu}$} & $\mathrm{MSL}_{f}(\mathrm{mg} / 100 \mathrm{kcal})$ & 2 & 2 & 0 & 0 & 0.3 \\
\hline & $\mathrm{MSL}_{\mathrm{s}}(\mathrm{mg} / \mathrm{d})$ & 2 & 2 & 2 & 0 & 2 \\
\hline \multirow[t]{2}{*}{ lodine } & $\mathrm{MSL}_{\mathrm{f}}(\mu \mathrm{g} / 100 \mathrm{kcal})$ & 165 & 165 & 0 & 0 & 22.5 \\
\hline & $\mathrm{MSL}_{s}(\mu \mathrm{g} / \mathrm{d})$ & 200 & 150 & 150 & 100 & 150 \\
\hline \multirow[t]{2}{*}{$\mathrm{Se}$} & $\mathrm{MSL}_{\mathrm{f}}(\mu \mathrm{g} / 100 \mathrm{kcal})$ & 47 & 47 & 2 & 0 & 9 \\
\hline & $\operatorname{MSL}_{s}(\mu \mathrm{g} / \mathrm{d})$ & 200 & 50 & 50 & 30 & 50 \\
\hline \multirow[t]{2}{*}{$\mathrm{Zn}$} & $\mathrm{MSL}_{\mathrm{f}}(\mathrm{mg} / 100 \mathrm{kcal})$ & 5 & 5 & 0 & 0 & 1.8 \\
\hline & $\mathrm{MSL}_{\mathrm{s}}(\mathrm{mg} / \mathrm{d})$ & 15 & 15 & 15 & $2 \cdot 25$ & 15 \\
\hline
\end{tabular}

$\mathrm{MSL}_{\mathrm{f}}$, maximum safe level for fortified foods; $\mathrm{MSL}_{\mathrm{s}}$, maximum safe level for dietary supplements. $* 100 \mathrm{kcal}=418 \mathrm{~kJ}$

To illustrate the utilisation of the method developed, Table 4 summarises the results obtained for the ten nutrients according to the five selected scenarios, in the event that fortified foods would account for $25 \%$ of fortifiable foods. This median, realistic assumption corresponds to a consumer for whom $25 \%$ of the foods that could be fortified are actually fortified.

The first two scenarios (using both ILSI's maximum safe levels for fortified foods) are those for which the UL are exceeded for all the nutrients at different percentile levels depending on the nutrient. To be more precise, in terms of vitamins, with scenarios 1 and 2 the UL may be exceeded by 20 to $30 \%$ of the population for vitamin D, $90 \%$ for vitamin $\mathrm{E}, 30$ to $40 \%$ for vitamin $\mathrm{B}_{6}$ and 5 to $10 \%$ for folic acid. Considering minerals, for the same two scenarios, the UL set for $\mathrm{Cu}$ intakes may be exceeded by $80 \%$ of the population, for iodine and $\mathrm{Zn}$ intakes by $60 \%$ of the population and for Se intakes by 20 to $30 \%$ of the population. Scenarios 3 and 4 are those which incur the least risk of exceeding the UL for all ten nutrients. Scenario 5 has fairly similar results to scenarios 3 and 4 . However, with scenario $4,30 \%$ of the population may still exceed the UL for folic acid and $5 \%$ for retinol. With scenario 5, 5 to $30 \%$ may exceed the UL for different minerals $(\mathrm{Ca}, \mathrm{Cu}$ and $\mathrm{Zn})$.

For each scenario, other assumptions on the individual market share have also been tested: $0 \%$ (no fortification, only supplementation, results not shown), $10 \%$, and $50 \%$. Opting for a $50 \%$ market share instead of $25 \%$ provided the same classification within the different scenarios, depending on their more-or-less conservative options, but led naturally to less protective results. For example, in scenarios 1 and 2 with the market share of $50 \%$, the UL set for $\mathrm{Zn}$ intakes may be exceeded by $95 \%$ of the population, whereas this limit was exceeded by 'only' $60 \%$ in the event of a market share of $25 \%$. Conversely, if the market share of fortified foods is quite low (10\%), the UL may be exceeded for $\mathrm{Zn}$ by a lower proportion of adults in the first two scenarios (30\% instead of $60 \%)$.

\section{Discussion and limits}

The present study aimed to test the acceptability of the $\mathrm{MSL}_{\mathrm{f}}$ and $\mathrm{MSL}_{\mathrm{s}}$ values set by different models to prevent consumers from exceeding the UL defined for vitamins and minerals. The maximum safe levels in fortified foods and dietary supplements result in nutritional intakes that may frequently (scenarios 1 and 2) or rarely (scenarios 3, 4 and 5) exceed the UL. When considering all ten nutrients simultaneously, this simulation approach demonstrated that scenarios 1 and 2 did not provide enough protection for consumers: the risk of exceeding UL varies depending on the nutrient but is real for all of them. Scenarios 3 and 4 seemed to be safer for consumers: the risk exists for only two nutrients (out of the ten) and for a small proportion of the population (5 or $10 \%$ with scenario $3,30 \%$ for folic acid with scenario 4$)$. The higher intakes observed with the first two scenarios can be explained mainly by the higher values of the maximum safe levels obtained for fortified foods (see Table 2). Indeed, an additional simulation considering only fortified foods shows that the UL are largely exceeded for certain vitamins and minerals (vitamin $\mathrm{E}, \mathrm{Cu}, \mathrm{Zn}, \mathrm{I}$ ). On the other hand, a simulation considering only supplements does not show that UL were exceeded to a significant extent. The initial mathematical model proposed by Flynn et al. ${ }^{(3)}$ did not take into account the higher intakes from supplements and led to $\mathrm{MSL}_{\mathrm{f}}$ values that are quite high. For this reason we remain cautious about the use of this model.

It should be pointed out that the main goal of the study was to describe the simulation method and not to provide the real 
Table 3. Nutrient intake distributions from the base diet (excluding dietary supplements and fortified foods) from the second French Individual and National Dietary Survey (INCA2): non-under-reporter adults $(n$ 1918)

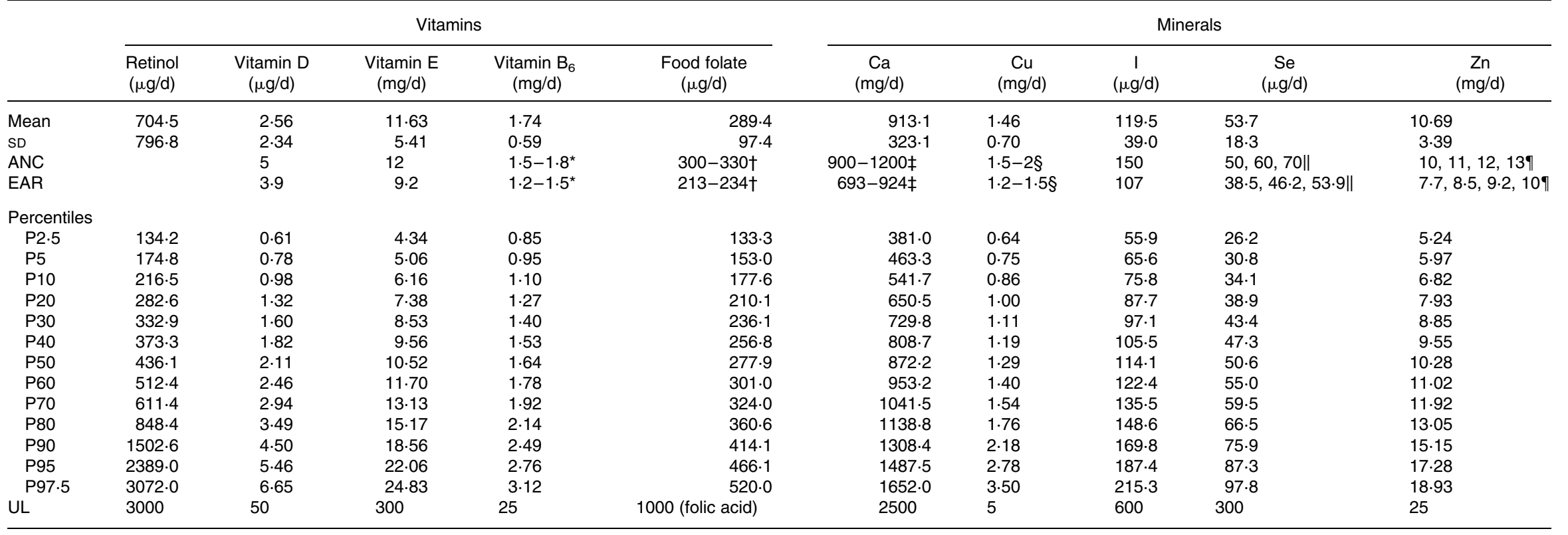

ANC, French population reference intake; EAR, estimated average requirement; $P$, percentile; UL, European tolerable upper intake level.

*ANC: male, $1 \cdot 8$; female, $1 \cdot 5$. EAR: male, $1 \cdot 5$; female, $1 \cdot 2$

†ANC: male, 330; female, 300. EAR: male, 234; female, 213.

FANC: male 20-64 years and female 20-54 years, 900; others, 1200. EAR: male 20-64 years and female 20-54 years, 693; others, 924

§ ANC: male 20-64 years, 2; others, 1.5. EAR: male 20-64 years, 1.5; others, $1 \cdot 2$.

II ANC: male 18-19 years and female 18-54 years, 50; male 20-64 years and female $55-75$ years, 60 ; others, 70 . EAR: male $18-19$ years and female 18-54 years, 38.5; male $20-64$ years and female $55-75$ years, $46 \cdot 2$; others, 53.9 ,

I ANC: female 18-19 years, 10; male 65-75 years and female $55-75$ years, 11 ; male $20-64$ years, 12 ; male $18-19$ years, 13 . EAR: female 18-19 years, 7.7 ; male $65-75$ years and female $55-75$ years, 8.5 ; male $20-64$ years,

9.2; male $18-19$ years, 10 
Table 4. Percentiles $(P)$ beyond which the European tolerable upper intake levels (UL) may be exceeded: results for the ten nutrients according to the five different scenarios in an adult population $(n 1918)^{*}$

\begin{tabular}{|c|c|c|c|c|c|c|}
\hline & UL & Scenario 1 & Scenario 2 & Scenario 3 & Scenario 4 & Scenario 5 \\
\hline \multicolumn{7}{|l|}{ Vitamins } \\
\hline Retinol & $3000 \mu \mathrm{g}$ & P95 & P95 & P95 & P95 & P90 \\
\hline Vitamin D & $50 \mu \mathrm{g}$ & P70 & P80 & - & - & - \\
\hline Vitamin E & $300 \mathrm{mg}$ & P10 & P10 & - & - & - \\
\hline Vitamin $B_{6}$ & $25 \mathrm{mg}$ & P60 & P70 & - & - & - \\
\hline Folic acid & $1000 \mu \mathrm{g}$ & P90 & P95 & - & P70 & - \\
\hline \multicolumn{7}{|l|}{ Minerals } \\
\hline $\mathrm{Ca}$ & $2500 \mathrm{mg}$ & P90 & - & - & - & P95 \\
\hline $\mathrm{Cu}$ & $5 \mathrm{mg}$ & P20 & P20 & - & - & P90 \\
\hline 1 & $600 \mu \mathrm{g}$ & P40 & P40 & - & - & - \\
\hline $\mathrm{Se}$ & $300 \mu \mathrm{g}$ & P70 & P80 & - & - & - \\
\hline $\mathrm{Zn}$ & $25 \mathrm{mg}$ & P40 & P40 & P90 & - & P70 \\
\hline
\end{tabular}

intakes of French consumers. Therefore, several assumptions and simplifications have been made.

First, the simulations performed in the present study concerned only adults and were therefore restrictive. In order to be comprehensive and offer more protection to the whole population, children should also be considered. Children could also consume the same fortified foods that adults consume and reach the UL more quickly because of lower values. But these simulations are more difficult to perform in the child population partly because all the parameters for setting the maximum safe level are not always available. For example, UL are not available for all nutrients for the different age ranges of children. The issue of which child age range should be taken into consideration is also raised. Some assumptions had to be made to remove some of these difficulties. Additionally, new simulations could be performed considering adults as well as children. In order to offer more protection, calculations of the $\mathrm{MSL}_{\mathrm{f}}$ should be carried out with the parameters of the 3- to 10-year-old children because they are more restrictive (UL for instance).

Second, we considered on one hand in our simulations that food supplement users consumed only one product per $d$ and we assigned the maximum daily dose calculated $\left(\mathrm{MSL}_{\mathrm{s}}\right)$ for the ten nutrients considered to all users. This hypothesis concerning supplement users is not maximalist. Indeed, about one-third of adult supplement users consumed more than one product per $d$ during the week in the INCA2 survey ${ }^{(12)}$. Therefore, the hypothesis of only one supplement per $\mathrm{d}$ could underestimate the real intakes and the possible exceeding of UL among supplements consumers. On the other hand, we supposed that all the supplements consumed contained the ten nutrients, which tends to overestimate actual intakes. Besides, simulations did not take into account the probable interactions between nutrients. Because of the complexity of modelling these interactions we were not able to take them into account. We assumed that they might be capable of limiting or increasing absorption and bioavailability.

It should also be pointed out that we treated as supplement users any individuals who declared consumption of such products during the $7 \mathrm{~d}$ of the survey and filled in a supplement record. Consequently, the percentage of users considered is lower than the percentage of long-term users over the 12-month period (11 v. 20\%). This choice seemed more rational, as micronutrient intakes from the base diet were also estimated during a $7 \mathrm{~d}$ period with no correction for intra-individual variability. However, the number of days needed to correctly assess intakes in France was estimated at $5 \mathrm{~d}$ for $\mathrm{Ca}$ and $10 \mathrm{~d}$ for vitamin $\mathrm{E}^{(21)}$. Except for retinol, whose intake is linked to rarely consumed foods such as offal, one may consider that an overestimation of high percentiles is not that significant and that the method is conservative overall.

Intakes of vitamins and minerals from fortified foods were simulated without considering any correlation with nutrient intakes from the base diet or with supplement intakes, because of the lack of data to support this correlation in France. However, the specific food habits of supplement users were considered because diet and supplement use were assessed at the same time for the same individuals. Indeed, previous publications have shown that supplement users do not have the same food habits as the general population ${ }^{(22)}$.

Moreover, it should be stressed that fortification and supplementation differ in terms of the consumer decision process. The decision to consume dietary supplements is voluntary and individual while the consumption of fortified food can be completely unintentional. However, nutritional intakes are estimated based on all sources (including fortified foods or supplements). Taking into account all the sources is justified in order to prevent consumers from exceeding UL. By choosing individual random exposure to fortified foods, we assume independence in fortified food consumption which is a strong hypothesis. Some data on the preferential purchasing of fortified foods are available in the INCA2 survey, through a self-administered questionnaire. The results show that $60 \%$ of the adults did not consider the fortified status of foods when choosing them. But, women chose fortified foods more frequently whereas men avoided them more frequently ${ }^{(12)}$. However, as one can consume fortified foods without knowing it, we chose to assign consumption of fortified foods to every subject of the sample, which was a conservative option for the food safety of consumers. Nevertheless, the method proposed here could be improved in the future by taking into account additional information that is not yet available on detailed consumer behaviour regarding fortified foods. 
Finally, the nutritional intakes are estimated based on all sources (i.e. fortified foods or supplements). Taking into account all the sources is justified in order to prevent consumers from exceeding UL. Although in France the consumption of dietary supplements is not very developed, in some other countries supplements may represent a nonnegligible source of nutrients in the daily diet ${ }^{23,24)}$.

The simulations performed in the present study were done after removing under-reporters who represent about one out of four individuals. In fact, some participants in dietary surveys tend to under-report their food intake. Consequently, most of dietary surveys report energy intake levels below needs. Therefore, we consider it justified to exclude underreporters to more accurately describe nutritional intakes. However, in order to check the possible influence of this choice on results, we performed the same simulation without the exclusion of under-reporters. The results were very close and the conclusions were the same.

All breakfast cereals in the French food composition table are already fortified. Therefore, we did not include them in the list of fortifiable foods. This assumption may have underestimated the present results because breakfast cereals could be more highly fortified than they presently are. Later, it could be possible to consider them as fortifiable food and to assign them the $\mathrm{MSL}_{\mathrm{f}}$ values set by the different models if these values are higher.

With the names and brands of products collected in the INCA2 study, an ad hoc nutritional composition table of fortified foods will be soon developed. It will be then possible to take into account the true intakes from this source. However, the probabilistic method remains useful for making assumptions about the possible evolution of the market share of fortifiable foods.

Very recently in 2008 , Flynn ${ }^{(25)}$ proposed an improvement of his model for setting the maximum safe levels in fortified foods by taking into account the supplement intake and not only the base diet intake. Testing the result obtained from this new model could be done in the future using our approach. It is also possible to modulate parameters from the model to integrate security factors in order to test other different options.

\section{Conclusion}

A rational risk assessment approach is useful to protect all consumers from the risk of exceeding UL. The simulation work conducted in the present study gives a clearer insight into this new situation. We assessed the maximum vitamin and mineral intakes in fortified foods and dietary supplements using different models.

The risk assessment approach developed to estimate the overall potential maximum nutritional intakes by integrating the maximum safe levels for fortified foods and dietary supplements set by different models is useful for ensuring consumer protection. Nevertheless, given the parameters considered, the results presented in this paper concern only the adult population. This method may be subsequently used to test any other maximum safe level for vitamins and minerals. In future, other hypotheses on parameters could be proposed to reinforce safety factors and lead to new maximum safe levels that could be tested with our method.
The probabilistic assessment approach is quite common in risk analysis in terms of food safety ${ }^{(26,27)}$. However, this kind of approach is not used very often in the field of nutritional regulation, and so this kind of work is quite innovative. It allows scenarios to be tested in terms of public health and consumer protection. This method can be used with any other proposed maximum safe limits for fortified foods or dietary supplements, for example, values proposed directly by risk managers without the support of a model. Furthermore, this probabilistic risk assessment method has been applied to French intake data, but it could also be applied to other national dietary surveys with food consumption data and occurrences of supplement intake.

\section{Acknowledgements}

The INCA2 study was supported by the French Food Safety Agency (AFSSA).

We would like to thank the Institut de Sondage Lavialle (ISL) team for the collection of the data and all the participants for their cooperation in the study.

The contributions of the authors were as follows: A. D. performed the simulations and wrote the manuscript; J.-L. V. supervised the simulations and contributed to interpretation and discussion; S. W., J. G. and E. K. contributed to the interpretation of the data in the nutrient risk assessment unit directed by I. M.; J.-L. V. and L. L. coordinated and supervised the INCA2 study; C. D., S. L., G. C. T., M. T., A. D., J. L. V. and L. L. contributed to the conception, design and data collection of the INCA2 study. All authors critically reviewed and approved the manuscript in its final version.

The authors declare no conflict of interest.

\section{References}

1. European Commission (2006) Regulation (EC) No. 1925/2006 of the European Parliament and of the Council of 20 December 2006 on the addition of vitamins, minerals and of certain other substances to foods (2006). Official Journal of the European Union, L404, 30.12.2006, 26. http://eur-lex.europa.eu/Lex UriServ/LexUriServ.do?uri=OJ:L:2006:404:0026:0038:EN:PDF (accessed June 2010).

2. Kelly JP, Kaufman DW, Kelley K, et al. (2005) Recent trends in use of herbal and other natural products. Arch Intern Med 165, 281-286.

3. Flynn A, Moreiras O, Stehle P, et al. (2003) Vitamins and minerals: a model for safe addition to foods. Eur J Nutr 42, 118-130.

4. Kloosterman J, Fransen HP, de Stoppelaar J, et al. (2007) Safe addition of vitamins and minerals to foods: setting maximum levels for fortification in The Netherlands. Eur J Nutr 46, 220-229.

5. Rasmussen SE, Andersen NL, Dragsted LO, et al. (2006) A safe strategy for addition of vitamins and minerals to foods. Eur $J$ Nutr 45, 123-135.

6. Richardson DP (2007) Risk management of vitamins and minerals: a risk categorisation model for the setting of maximum levels in food supplement and fortified food. Food Sci Technol Bull Funct Foods 4, 51-66.

7. Domke A, Großklaus R, Niemann B, et al. (2005) Use of Minerals in Foods - Toxicological and Nutritional-Physiological Aspects. Berlin: Federal Institute for Risk Assessment (BFR).

8. Domke A, Großklaus R, Niemann B, et al. (2005) Use of Vitamins in Foods - Toxicological and Nutritional-Physiological Aspects. Berlin: Federal Institute for Risk Assessment (BFR). 
9. French Food Safety Agency (AFSSA) (2001) Report from the AFSSA Expert Committee on Human Nutrition on food fortification by vitamin and mineral: meeting the nutritional and safety needs of the consumers. Maisons Alfort, France: French Food Safety Agency (AFSSA); 8 November 2001 (transcripted version 15 January 2002). http://www.afssa.fr/ Documents/NUT2000sa0239Ra.pdf (accessed June 2010).

10. French Food Safety Agency (AFSSA) (2004) Specification for the Selection of a Nutrient-Vector Food Pair. Maisons Alfort, France: French Food Safety Agency (AFSSA). http://www. afssa.fr/Documents/NUT-Ra-Alimentsvecteurs.pdf (accessed June 2010).

11. Touvier M, Lioret S, Vanrullen I, et al. (2006) Vitamin and mineral inadequacy in the French population: estimation and application for the optimization of food fortification. Int $J$ Vitam Nutr Res 76, 343-351.

12. French Food Safety Agency (AFSSA) (2009) Individual and National Study on Food Consumption 2 (INCA2) 2006-2007 (report in French and summary in English). Maisons Alfort, France: French Food Safety Agency (AFSSA). http://www. afssa.fr/Documents/PASER-Ra-INCA2.pdf http://www.afssa.fr/ Documents/PASER-Sy-INCA2.pdf (accessed June 2010).

13. French National Institute for Statistics and Economic Studies (INSEE) (1999) National Institute for Statistics and Economic Studies - Recensement général de la population (Population census). Paris: INSEE. http://www.recensement-1999.insee.fr/ RP99/rp99/page_accueil.paccueil (accessed June 2010).

14. Sautory O (1993) La macro CALMAR - Redressement d'un échantillon par calage sur marges (SAS CALMAR macro - Adjustment of a sample using calibration on margins). Paris: INSEE. http://www.insee.fr/fr/methodes/outils/calmar/ doccalmar.pdf (accessed June 2010).

15. Goldberg GR, Black AE, Jebb SA, et al. (1991) Critical evaluation of energy intake data using fundamental principles of energy physiology: 1 . Derivation of cut-off limits to identify under-recording. Eur J Clin Nutr 45, 569-581.

16. Hercberg S, Deheeger M \& Preziosi P (1994) SU-VI-MAX. Portions Alimentaires: Manuel Photos pour l'Estimation des Quantités (SU-VI-MAX. Food Portions: Photograph Manual for Quantity Estimation). Paris: Polytechnica.

17. French Data Centre on Food Quality (CIQUAL) (2008) Table de composition nutritionnelle des aliments (French Food Composition Table). Maisons Alfort, France: French Food Safety Agency (AFSSA). http://www.afssa.fr/TableCIQUAL/ (accessed June 2010).
18. Renwick AG, Flynn A, Fletcher RJ, et al. (2004) Risk-benefit analysis of micronutrients. Food Chem Toxicol 42, 1903-1922.

19. European Food Safety Authority (2006) Tolerable Upper Intake Levels for Vitamins and Minerals by the Scientific Panel on Dietetic Products, Nutrition and Allergies (NDA) and Scientific Committee on Food (SCF). Parma: European Food Safety Authority. http://www.efsa.europa.eu/EFSA/efsa_locale-1178620753812_ 1178633962601.htm (accessed June 2010).

20. French Government (2006) Arrêté du 9 mai 2006 relatif aux nutriments pouvant être employés dans la fabrication des compléments alimentaires (Order of 9 May 2006 on nutrients that can be used in the manufacture of food supplements). In Journal Officiel de la République Française. JORF no. 123, 28 May 2006, p. 7977. http://www.legifrance.gouv.fr/jopdf/ common/jo_pdf.jsp?numJO=0\&dateJO=20060528\&numTexte $=$ 7\&pageDebut=07977\&pageFin=07979 (accessed June 2010).

21. Mennen L, Bertrais S, Galan P, et al. (2002) The use of computerised $24 \mathrm{~h}$ dietary recalls in the French SU.VI.MAX Study: number of recalls required. Eur J Clin Nutr 56, 659-665.

22. Touvier M, Niravong M, Volatier JL, et al. (2009) Dietary patterns associated with vitamin/mineral supplement use and smoking among women of the E3N-EPIC cohort. Eur J Clin Nutr 63, 39-47.

23. Balluz LS, Okoro CA, Bowman BA, et al. (2005) Vitamin or supplement use among adults, behavioral risk factor surveillance system, 13 states, 2001. Public Health Rep 120, 117-123.

24. Harrison RA, Holt D, Pattison DJ, et al. (2004) Are those in need taking dietary supplements? A survey of 21923 adults. Br J Nutr 91, 617-623.

25. Flynn A (2009) Micronutrient intakes in Europe: conclusions and implications. In Micronutrient Landscape of Europe: Comparison of Intakes and Methodologies with Particular Regard to Higher Consumption. Summary report of a workshop held in April 2008 organised by the ILSI Europe Addition of Nutrients to Food Task Force [J Howlett and N Binns, editors]. http:// www.ilsi.org/Publications/Micronutrient\%20Report\%202009.pdf (accessed June 2010).

26. Sioen I, Bilau M, Verdonck F, et al. (2008) Probabilistic intake assessment of polybrominated diphenyl ethers and omega-3 fatty acids through fish consumption. Mol Nutr Food Res 52, 250-257.

27. Cao H, Suzuki N, Sakurai T, et al. (2008) Probabilistic estimation of dietary exposure of the general Japanese population to dioxins in fish, using region-specific fish monitoring data. J Expo Sci Environ Epidemiol 18, 236-245. 
Appendix. Short presentation of the different models setting the maximum safe level for fortified foods $\left(\mathrm{MSL}_{\mathrm{f}}\right)$ and maximum safe level for dietary supplements $\left(M S L_{s}\right)$

\begin{tabular}{|c|c|c|c|}
\hline Model & $\begin{array}{l}\text { Type of product concerned: } \\
\text { supplements or fortified foods }\end{array}$ & $\begin{array}{l}\text { Formula to set the } \\
\text { maximum safe levels }\end{array}$ & Parameters \\
\hline ILSI/Flynn ${ }^{(3)}$ & Fortified foods & $\begin{array}{l}\mathrm{MA}=\mathrm{UL}-\mathrm{Cl}_{95} \\
\mathrm{FA}=\left(\mathrm{UL}-\mathrm{Cl}_{95}\right) /(0.5 \times 36 \times \mathrm{PFF})\end{array}$ & $\begin{array}{l}\text { MA: maximum amount of each nutrient which may be added } \\
\text { to the diet as a whole with little risk of adverse health effect in the population } \\
\text { FA: amount of each nutrient which may be added safely to each } 100 \mathrm{kcal}^{*} \\
\text { portion (corresponding to } \mathrm{MSL}_{\mathrm{f}} \text { ) } \\
\text { UL: tolerable upper intake level } \\
\text { Cl } \\
\text { PFF: furrent intakes of micronutrient from non-fortified food at the } 95 \text { th percentile } \\
\text { PFtially fortifiable foods in the market }\end{array}$ \\
\hline DFVR/Rasmussen ${ }^{(5)}$ & Fortified foods & $\mathrm{FA}=\left(\mathrm{UL}-\left(\mathrm{Cl}_{95}+\mathrm{SI}\right)\right) /\left(\mathrm{El}_{95} \times \mathrm{PFF}\right)$ & $\begin{array}{l}\text { FA: amount of each nutrient which may be added safely to each } 100 \mathrm{kcal}^{*} \text { portion } \\
\text { (corresponding to } \mathrm{MSL}_{\mathrm{f}} \text { ) } \\
\text { UL: tolerable upper intake level } \\
\mathrm{Cl}_{95} \text { : current intakes of micronutrient from non-fortified food at the } 95 \text { th percentile } \\
\text { SI: supplement intake } \\
\text { EI } \\
\text { PFF: current energy intake at the } 95 \text { th percentile } \\
\text { PFF of potentially fortifiable foods in the market }\end{array}$ \\
\hline ERNA/Richardson ${ }^{(6)}$ & Supplements & $\begin{array}{l}\text { For vitamins: } \mathrm{MSL}_{\mathrm{s}}=\mathrm{UL}-(\mathrm{MHI} \times 1 \cdot 5) \\
\text { For minerals: } \mathrm{MSL}_{\mathrm{s}}=\mathrm{UL}-(\mathrm{MHI} \times 1 \cdot 1)+\mathrm{IW}\end{array}$ & $\begin{array}{l}\text { MSL } L_{s} \text { : maximum safe level for supplements }(\mathrm{mg} \text { or } \mu \mathrm{g} / \mathrm{d}) \\
\mathrm{UL} \text { : tolerable upper intake level } \\
\text { MHI: mean highest dietary intake, i.e. } 97 \cdot 5 \text { th percentile } \\
\text { IW: mean highest intake from water }\end{array}$ \\
\hline BFR/Domke ${ }^{(7,8)}$ & Fortified foods and supplements & $\begin{array}{l}\mathrm{R}=\mathrm{UL}-\mathrm{DINF} \\
\mathrm{R}=\mathrm{R}_{\mathrm{S}}+\mathrm{R}_{\mathrm{F}}\end{array}$ & $\begin{array}{l}\text { R: residual amount for safe addition to foods including dietary supplements } \\
\text { (tolerable intake via dietary supplements + tolerable intake via fortified food) } \\
\text { DINF: dietary intake by normal food (95th or } 97.5 \text { th percentile of nutrient intake) } \\
\text { R }_{S} \text { : tolerable intake via dietary supplements (corresponding to } \mathrm{MSL}_{\mathrm{s}} \text { ) } \\
\mathrm{R}_{\mathrm{F}} \text { : tolerable intake via fortified food (corresponding to } \mathrm{MSL}_{\mathrm{f}} \text { ) }\end{array}$ \\
\hline French regulation ${ }^{(20)}$ & Supplements & Not a mathematical model & Values set in the French regulation order of 9 May 2006 \\
\hline
\end{tabular}

ILSI, International Life Sciences Institute; DFVR, Danish Institute for Food and Veterinary Research; ERNA, European Responsible Nutrition Alliance; BFR, Federal Institute for Risk Assessment.

$* 100 \mathrm{kcal}=418 \mathrm{~kJ}$. 